\title{
O IMPACTO DAS “FAKE NEWS” NA EDUCAÇÃO DOS JOVENS DO BRASIL
}

\author{
Davi Valois Cardoso ${ }^{1}$
}

\begin{abstract}
RESUMO: As fakes news podem ser consideradas como um grande agravo à aquisição de conhecimento na atualidade pois distorcem a realidade e modificam o teor verossímil das informações. Desde tenra idade o imediatismo, a polemização e a contundência causadas pelas notícias rápidas atraem muito a atenção da população, principalmente a mais jovem. Com os objetivos mais distintos, atingindo diversas camadas da sociedade e com os mais diversos níveis de impactos sociais, as fake news merecem muita atenção no atual contexto de difusão extremamente rápida das notícias mundo afora. Neste cenário, esta breve revisão literária tentará denotar o impacto dessas falsas notícias e suas propagações em meio às crianças, jovens e diante da literatura científica no Brasil.
\end{abstract}

Palavras-chave: "Fake news". Educação. Brasil.

ABSTRACT: Fake news can be considered as a great aggravation to the acquisition of knowledge nowadays because they distort reality and modify the credible content of information. From an early age, the immediacy, controversy and forcefulness caused by the rapid news attract a lot of attention from the population, especially the youngest. With the most distinct objectives, reaching different layers of society and with the most diverse levels of social impacts, fake news deserves a lot of attention in the current context of extremely rapid dissemination of news worldwide. In this scenario, this brief literary review will attempt to denote the impact of these false

I Graduado em Fisioterapia pela Universidade Católica do Salvador (UCSAL), especialista em Reabilitação Neurofuncional pela Universidade Social da Bahia (UNISBA), pós-graduado em Docência do Ensino Superior e em Traumato-ortopedia pela Faculdade FUTURA. Teve experiências no campo docente como preceptor de estágio e residência multiprofissionais na Universidade Federal da Bahia (UFBA) e Universidade Estadual da Bahia (UNEB) respectivamente. Atualmente, os atendimentos particulares em QUIROPRAXIA CLÍNICA a domicílio com pacientes neurológicos, ortopédicos e geriátricos, ditam sua atuação profissional. http://lattes.cnpq.br/5976361108940124 Email: Graduado em Fisioterapia pela Universidade Católica do Salvador (UCSAL), especialista em Reabilitação Neurofuncional pela Universidade Social da Bahia (UNISBA), pós-graduado em Docência do Ensino Superior e em Traumato-ortopedia pela Faculdade FUTURA. Teve experiências no campo docente como preceptor de estágio e residência multiprofissionais na Universidade Federal da Bahia (UFBA) e Universidade Estadual da Bahia (UNEB) respectivamente. Atualmente, os atendimentos particulares em quiropraxia clínica em domicílio com pacientes neurológicos, ortopédicos e geriátricos, ditam sua atuação profissional. http://lattes.cnpq.br/5976361108940124 . Email: davi.valois@gmail.com 
news and its spread among children, young people and in the face of scientific literature in Brazil.

Keywords: Fake news. Education. Brazil.

\section{INTRODUÇÃO}

Desde que a internet surgiu em meados da década de ig6o a humanidade está passando por uma rápida transformação em todos os sentidos possíveis. Segundo Ongaro (2019), um dos impactos mais profundos trazidos pela internet é a comunicação de massa através de aplicativos de mensagens instantâneas. Esses aplicativos conseguiram dar voz a muitos que sempre foram silenciados. Muitas informações não precisam necessariamente de uma reportagem bem elaborada ou de algum noticiário ou jornal específico para chegar ao conhecimento do público, basta que alguém tenha acesso a um smartphone e determinados eventos já viram notícias. Um evento bem recente foi o assalto cinematográfico ocorrido em uma agência bancária da cidade de Criciúma no estado de Santa Catarina e que foi transmitido para toda a internet em diferentes ângulos. Outros exemplos, como as inúmeras denúncias de abuso de poder por parte de policiais, casos de racismos, homofobia e diversas outros crimes só passaram a fazer parte dos grandes noticiários graças aos inúmeros amadores mundo afora.

No entanto, neste cenário há também inúmeras vozes dissonantes, que em vez de produzir verdadeiras notícias, produzem as chamadas fake news, definidas por Allcott e Gentzkow (2017) como sendo aquelas notícias intencionalmente falsas criadas e espalhadas com a intenção de enganar. Por isso, conforme mostra Burston (2018), o principal intuito das fake news não é outro senão fazer com que seus conteúdos pareçam ser legítimos, desde a maneira como as informações são transmitidas até a estruturação e nome do domínio dos sites. Os estudos de Alcott e Gentzkow (2017) apontam que são duas as principais motivações geradoras de fake news: a monetária e a ideológica. A primeira parte de interesses comerciais e financeiros; a segunda tem como objetivo vincular ao aliciamento de pensamentos e atitudes. 
Um exemplo levantado por muitos estudiosos e que colocou em evidência o fenômeno das fake news, foi o que ocorreu durante as eleições americanas de $2016 \mathrm{em}$ que concorreram à presidência Hillary Clinton e Donald Trump. Diversas notícias falsas com teor ideológico foram feitas para atacar Clinton, como a acusação de comunista, anticristã e outros de caráter meramente ideológico. $\mathrm{O}$ mesmo pôde ser observado nas últimas eleições presidenciais no Brasil com a elaboração de diversas fake news ideológicas como o "kit gay", a ideologia de gênero e tantos outros ataques.

Neste cenário construído à base de mentiras, toda a sociedade é prejudicada. No entanto, quando se trata de educação, o tema ainda se torna ainda mais prejudicial. O que ensinar e o que aprender em um contexto, em que, cada um pode construir sua própria verdade de acordo com sua perspectiva, muitas vezes limitadora? O que vale mais: um estudo realizado baseados em evidências, testado e questionado, ou orientações esquizofrênicas baseadas no "eu acho"? No mundo cada vez mais refém de fake news, quase todas elas inspiradas em teorias de conspiração, a educação e por consequência a ciência corre grande perigo. Neste sentido, este trabalho levanta a seguinte problemática: qual o impacto das fake news na educação? O objetivo principal é encontrar respostas a esta problemática através de estudos publicados nos últimos cinco anos.

\section{METODOLOGIA}

Essa pesquisa foi elaborada a partir de revisão da literatura nas bases de dados Scielo e Google Acadêmico no período entre 2015 e 2020. As palavras-chave utilizadas foram "fake News" e "educação" numa busca na literatura nacional. Foram critérios de exclusão: trabalhos realizados antes do ano 2015; revisões e mapeamentos sistemáticos de literatura; estudos que não respondiam à questão norteadora; estudos não publicados em língua portuguesa; e estudos de caso. Como resultado da busca junto às bases escolhidas, foram encontrados 96 artigos, cuja análise ocorreu em três fases. A primeira, foi realizada a análise dos títulos. Nesta fase foram identificados e excluídos 33 artigos, conforme os critérios de exclusão estabelecidos. $\mathrm{Na}$ segunda fase houve a leitura dos resumos e por não contribuir para a responder ao problema 
proposto neste trabalho, foram excluídos outros 25 trabalhos. Por último, a terceira fase foi feita a análise completa dos artigos, sendo excluídos mais 22 trabalhos. Ao longo da pesquisa foram excluídos 19 trabalhos realizados antes de 2015; foram encontrados e excluídos 24 trabalhos em outra língua; 22 trabalhos que não apresentavam soluções para o problema deste trabalho; ıo trabalhos de revisão e mapeamentos sistemáticos de literatura; e outros 5 que apresentavam estudos de caso. Dessa forma, 16 artigos foram incluídos na pesquisa.

Ressalta-se que durante a leitura integral dos artigos foi possível classificar os estudos em 3 categorias distintas: o impacto das fake news na educação infantil, nos jovens do ensino médio e na divulgação científica.

\section{DESENVOLVIMENTO}

Neste tópico será feita a apresentação geral dos estudos classificados de acordo com as categorias apresentadas pelos trabalhos pesquisados autores. Cada estudo foi analisado em busca de respostas às questões norteadoras desta pesquisa e, em resposta, apresentamos diversas soluções e estratégias para auxiliar a comunidade surda em seus processos de ensino e aprendizagem.

\subsection{O impacto das fake news na educação infantil}

Muito recentemente viralizou na internet a notícia de uma criança de quatro anos que pegou o celular dos pais, entrou em um aplicativo de comida e acabou gastando $\mathrm{R} \$ 400.00$ reais em lanches. Apesar de ser um caso aparentemente engraçado, no entanto é um indicador da vulnerabilidade das crianças em contato com os meios tecnológicos. Com efeito, diversos estudos apontam que os menores são os mais vulneráveis e os mais propensos a cair em algum tipo de golpe, sendo eles o elo fraco, ou a brecha que fraudadores encontram para ter acesso de forma ilegal a informações pessoais. Além desses problemas há ainda outros, como cyberbullying, as mensagens de incentivo a automutilação e suicídio, pedofilia e tantos outros aos quais as crianças estão mais vulneráveis.

De acordo com um especialista ouvido por uma reportagem das jornalistas do site Tribuna Online, Proscholdt e Simony (2020), os pais devem estar atentos aos 
aplicativos de mensagens instantâneas, principalmente aos grupos temáticos, como de famosos, fã-clubes e de jogos, uma vez que nestes grupos podem ter pessoas infiltradas para atrair vítimas através de fake news, geralmente jogando iscas, como por exemplo, um aparente e inofensivo banner com publicidade para ganhar bonificação em jogos, mas que na verdade esconde um link com código malicioso, que pode ser qualquer coisa, desde um espião que tem acesso à câmera e à galeria de fotos, até outros vírus mais danosos ao próprio aparelho.

O impacto das fake news para as crianças ganhou mais evidência depois da publicação do relatório da pesquisa Tic Kids Online Brasil: Pesquisa Sobre o Uso da Internet por Crianças e Adolescentes no Brasil (2017), que mostrou que 24,3 milhões de crianças e adolescentes são usuários de internet, sendo que desse, 31\% disseram que não são capazes de verificar se uma informação encontrada na rede é correta ou não. É, pois neste cenário preocupante que tem surgido diversos estudos mostrando algumas estratégias pedagógicas para diminuir o impacto das fake news sobre as crianças.

Silva (2018), por exemplo apresenta diversas estratégias educacionais, como a proposta o manual Journalism, fake news or Disinformation elaborado pela Organização das Nações Unidas para a Educação, a Ciência e a Cultura (UNESCO) com o objetivo de refletir sobre como a tecnologia digital e as redes sociais podem causar distúrbios de informação. Outra proposta para amenizar o efeito das fake news sobre as crianças fora apresentada pela Agenzia Nazionale Stampa Associata (ANSA), cuja inspiração foi o método de uma professora norte-americana que incentiva os jovens a pensarem de forma crítica, a serem criativos e colaborativos, além de ensinar a buscar dados e fontes de forma correta. No entanto, estes são apenas alguns exemplos e que o Brasil não precisa ir longe para se inspirar, conforme destaca reportagem publicada no site Educação Infantil (2018), em que destaca que a própria Base Nacional Comum Curricular (BNCC), já aponta a necessidade de desenvolver a criticidade dos estudantes no meio digital, conforme destacado abaixo:

A viralização de conteúdos/publicações fomenta fenômenos como o da pós-verdade, em que as opiniões importam mais do que os fatos em si. Nesse contexto, torna-se menos importante checar/verificar se algo aconteceu do que simplesmente acreditar que aconteceu (já que isso vai ao 


\begin{abstract}
encontro da própria opinião ou perspectiva) [...] eis, então, a demanda que se coloca para a escola: contemplar de forma crítica essas novas práticas de linguagem e produções, não só na perspectiva de atender às muitas demandas sociais que convergem para um uso qualificado e ético das TDIC - necessário para o mundo do trabalho, para estudar, para a vida cotidiana etc. -, mas de também fomentar o debate e outras demandas sociais que cercam essas práticas e usos. É preciso saber reconhecer os discursos de ódio, refletir sobre os limites entre liberdade de expressão e ataque a direitos, aprender a debater ideias, considerando posições e argumentos contrários (BRASIL, 2017, p. 68).
\end{abstract}

Neste sentido, os estudos apontam que as crianças são as mais afetadas pelas fake news e por isso a educação deve ser um campo privilegiado aos quais elas possam formar suas próprias opiniões e saber lançar um olhar crítico sobre as informações que lhes chegam através da internet. É importante salientar que da mesma forma que elas são atingidas por falsas notícias, elas também o são pelas boas e verdadeiras informações.

\title{
3.2 Fake news e os jovens do ensino médio
}

Se para os pequenos a fake news podem causar grandes problemas, para os jovens com idade do ensino médio pode ser mais perigoso ainda, pois além deles mesmos sofrerem, eles podem ser agentes propagadores de notícias falsas. Com efeito, algumas pesquisas comprovam que os jovens são mais susceptíveis a acreditar e espalhar fake news, como aponta pesquisadores do Instituto Tecnológico de Massachusetts (MIT) e publicada na revista Science, ao revelar uma notícia falsa tem $70 \%$ mais chance de ser compartilhada.

Outra pesquisa fora realizada pela DNPontocom e apresentada por reportagem do site Neo Mundo (GERAÇÃO Z, 20I8), mostra que os jovens são os mais propensos a compartilharem fake news, uma vez são usuários mais ativos e também aqueles que menos checam as informações do conteúdo. Esta pesquisa mostrou ainda que a geração $Z$, isto é, aqueles nascidos entre 1990 e 2010, leem apenas o título das informações, antes de compartilhar. Já a geração Y, aqueles nascidos entre 1980 e 1990 possui maior cuidado e checam as fontes antes de compartilhar. Por sua vez, a geração X, os nascidos até o início dos anos 1980, são menos influenciados e, por conseguinte, são menos propagadores de fake news, pois são mais influenciados por intelectuais e sempre leem a notícia completa. 
Segundo Oliveira (2018), um dos elementos que mais atrai os jovens para as fake news é o fator novidade e polêmica e, com efeito, "a novidade atrai a atenção humana porque atualiza nossa compreensão de mundo". Quando a informação é nova, não é só surpreendente, mas mais valiosa, no sentido de que aquele que a possui ganha status social (OLIVEIRA, 2018, p. 53). Desta forma, o que se verifica é que aquele jovem, quando de posse de uma notícia nova, o senso crítico é a última coisa que lhe passa pela cabeça. Santo e Miranda (2020), também tem essa mesma percepção ao afirmar que para o jovem em idade escolar, uma notícia nova, mesmo que falsa é muito mais importante que qualquer conteúdo ministrado pelo professor, por isso muitas vezes essas fake news acabam se tornando um instrumento para se sobrepor até mesmo ao professor.

\subsection{Fake news e divulgação científica}

É fato que 2020 colocou em evidência a ciência, a pesquisa científica, os métodos científicos e tudo relacionado com o fazer da ciência. Segundo dados do Google Trends Brasil houve um "aumento repentino" pelas buscas relacionados à palavra ciência em sua plataforma de buscas. Com efeito, de fevereiro para março de 2020 houve aumento de mais de I00\% nas buscas, passando de 34 para 68. Tal interesse pela ciência, no entanto, pode ter explicações em diversos acontecimentos na política brasileira: de um lado aqueles que defendem a ciência e de outro aqueles que a simplesmente a ignora em busca de resultados imediatistas. Com isso a ciência em si não tem muito interesse, mas é usada como argumento falacioso para evidenciar o erro do oponente. Por um outro lado ainda pior, a ciência vem sendo usada como pano de fundo para o espalhamento de fake news de todas as ordens, basta dar uma rápida passagem pela internet e verificar a quantidade de noticias falsas com ar de ciência sobre os mais variados assuntos, desde aquecimento global até a suposta cura do Covid-ig.

Segundo Martins (2018), a ciência, mais que outros assuntos, é amplamente atingidas pelas fake news, pois é de grande de interesse público, principalmente o público político. Outro fator observado pela pesquisadora é que por depender de 
pesquisas, teses e análises científicas, as ciências acabam sofrendo maior impacto das notícias que são imediatas e apresentam resultados rápidos para problemas que estão acontecendo agora. Isso pode ser verificado em relação à pandemia do novo coronavírus, enquanto cientistas do mundo todo trabalham à procura de uma cura, milhares de fake news circulam apresentando a suposta cura e tratamentos para a doença.

Para Gomes et al (2020), o aumento de fake news envolvendo a ciência está maior ainda porque pode ser encontrada nos mais variados espaços e não apenas nos artigos científicos. Hoje uma descoberta cientifica pode ser apresentada em um programa de televisão, em revistas, jornais e em redes sociais. No entanto, as autoras questionam: será que tudo aquilo que circula nesses meios está pautado em uma literatura científica de fato? Essa talvez fosse uma grande oportunidade de democratização da informação, entretanto esse território virtual se manifesta repleto de disputas discursivas entre o real e a ficção. Para Ongaro (2019), o fenômeno da democratização da informação fez com que o território virtual se transformasse em um território de disputas discursivas entre o real e a ficção.

Carvalho e Mateus (2018), recorrem ao conceito de pós-verdade para explicar o avanço cada vez mais crescente de fake news. Segundo estes estudiosos, o que importa não é a verdade em si, mas a persuasão. Desta forma, a verdade é banalizada, isto é,

Dados objetivos são ignorados, e o apelo na formação da opinião junto ao público fala mais alto que a veracidade dos fatos, criando uma confusão sobre a realidade. Não chega a ser uma mentira, nem tampouco uma verdade. Daí se torna uma arma tão igual ou mais poderosa que as Fake News, pois apela para um discurso emotivo populista (CARVALHO; MATEUS, 2018, p. 72).

É a partir deste modo de colocar a mentira que Martins (2018), analisa que para uma notícia falsa ganhe adeptos, requer formas muito potentes para sustentar-se e uma delas é exatamente o silêncio. A estudiosa observa que na fake news a verdade é silenciada, pois emite-se uma parte comprovável da mensagem, mas outra igualmente verdadeira é omitida. Então fica-se a cargo do leitor entender e interpretar a insinuação, a pressuposição e o subentendimento. Outro fator 
determinante é a falta de contexto e a inversão da relevância com que as notícias falsas são passadas adiante.

Esta técnica ao qual Martins descreve é comprovada por Mesquita et al (2020), através de um exemplo simples. Em 28 de dezembro de 2017, o presidente dos Estados Unidos da América, Donald Trump fez a seguinte publicação no Twitter: “ $\mathrm{Na}$ costa leste é possível que tenhamos a véspera de ano novo mais fria já registrada. Talvez pudéssemos usar um pouco desse aquecimento global que nosso país, mas não os outros, vão pagar trilhões de dólares para evitar”. O que se observa claramente um descomprometimento com a verdade e a utilização de fatos comprovados cientificamente com informações falsas.

A partir de uma análise mais aprofundada, Gouvêa (2017), identifica três variáveis fundamentais para que notícias falsas se sobreponha à ciência, são eles: logos, pathos e ethos. O primeiro é a forma lógica na qual o orador se expressa pelo discurso. O segundo diz respeito à forma com a qual o orador invoca as emoções do seu público. E o terceiro é a apresentação da própria mensagem, geralmente como figura competente. A fim de demonstrar esta estrutura em uma fake News, Gomes et al (2020), prepararam uma ilustração bastante esclarecedora conforme apresentada na Figura I.

Figura I: Estrutura persuasiva de fake News

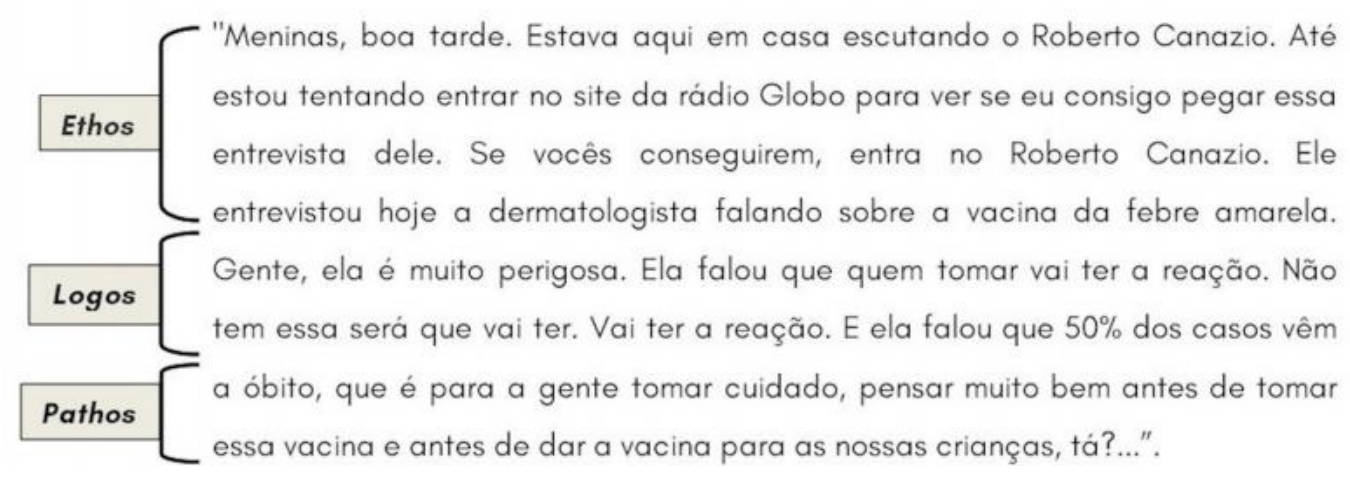

Fonte: Gomes et al (2020, p. 4).

Neste exemplo o ethos é o apresentador de uma rádio a dermatologista. Já o logos é apresentado através de dados numérico e de linguagem técnica da área saúde, 
invocando assim racionalidade e lógica. Por fim, o pathos é expresso quando a própria mensagem se mostra altamente competente ao ponto evitar o óbito de crianças e adultos.

É, pois neste cenário que a divulgação científica deve se ater a diversos fatores para que possa comunicar de forma eficiente e evitar de ser usada fora de contexto para alimentar notícias falsas. Neste sentido Aro e Gomes (2017), destaca que é necessário sempre uma boa comunicação entre cientista e jornalistas na divulgação da ciência. Por outro lado, os dois lados devem melhorar sempre para se adequar o vocabulário na comunicação científica. E mais uma vez, estudiosos ressaltam a importância da educação mediática para não cair e repassar as fakes news.

\section{CONCLUSÃO}

Através deste estudo foi possível perceber que, apesar da importância e urgência do tema, ainda são poucos os estudos relacionados aos impactos das fake news na educação. No entanto, os estudos existentes são profundos e bem sólidos.

Fica evidente também que se por um lado há poucos estudos que descrevem os impactos das fake news na educação, são diversos os estudos que levantam inúmeras estratégias didáticas para se trabalhar o tema na educação.

Com efeito, todos os estudos apresentados nesta pesquisa apontam que a melhor e mais eficiente forma de diminuir o impacto das fake news na educação é através da própria educação. Estudos como o de Aro e Gomes (2017), apontam que as contribuições das próprias fake news oferecem para a formação de leitores críticos diante de situações de notícias falsas. Outras pesquisas, como a de Ongaro (2019), traz importantes pistas sobre a importância do papel da escola para o processo de compreensão da mídia-educação e da necessidade de uma alfabetização midiática e informacional. $\mathrm{Na}$ mesma linha, grandes instituições, como a UNESCO ressalta a necessidade urgente de estabelecer o letramento midiático que não consiste apenas na leitura e na escrita, mas e sobretudo na compreensão de ser sujeito no interior das práticas sociais, isto é, que aquilo que se lê deve necessariamente ser questionado e discutido. 
Este estudo demonstrou ainda que as crianças, os adolescentes e jovens são os mais vulneráveis às fake news, uma vez que eles ainda não têm a capacidade cognitiva totalmente desenvolvida para separar o real da mentira. No entanto, são eles os possíveis de serem mais bem educados para o enfrentamento às notícias falsas. Quanto aos meios de introduzir essa temática na educação, a BNCC parece ter se antecipado ao apontar ao menos três alternativas. A primeira diz respeito às condições de acesso às tecnologias e em contexto escolar; a segunda, ressalta a importância da formação dos docentes para o uso das tecnologias e educação; e a terceira, aponta a criticidade para lidar com essas utilizações. Percebe-se assim que negar esta realidade não é uma alternativa. Antes é preciso encarar esta realidade e através da educação crítica, transformá-la.

\section{REFERÊNCIAS}

AlCOTT, H; GENTZKOW, M. Social Media and Fake News in the 2016 Election. Journal of Economic Perspectives, v. 3I, n. 2, 2017.

ARO, Mariana Lansttai Bevilaqua; GOMES, Nataniel dos Santos. As fake news como contribuição na formação do leitor crítico. Revista Philologus, ano 23, n. 69, 2017 .

BRASIL. Base Nacional Comum Curricular. Brasília: MEC, 2017.

BURSTON, A. et. al. A Citizen's Guide to Fake News. Center for Information Technology \& Society, 2018.

CARVALHO, Mariana Freitas Canielo; MATEUS, Cristielle Andrade. Fake news e desinformação no meio digital: análise da produção científica sobre o tema na área de ciência da informação, 2018.

EDUCAÇÃO INFANTIL. Fake news na educação: como educar as crianças? Disponível em: https://educacaoinfantil.aix.com.br/fake-news-na-educacao/ Acesso em: or dez. 2020.

GERAÇÃO $Z$ é mais vulnerável à fake news. Neo Mondo. Disponível em: http://www.neomondo.org.br/2018/o7/12/geracao-z-e-mais-vulneravel-a-fakenews/ Acesso em: or dez. 2020.

GOMES, Sheila Freitas et al. Fake News Científicas: Percepção, Persuasão e Letramento. Ciência \& Educação, Bauru, v. 26, 2020. 
GOUVÊAA, L. H. M. Argumentação pela emoção: um caminho para persuadir. Rio de Janeiro: UFRJ, 2017

MARTINS, Leandra Rajczuk. Fake news e os impactos na divulgação científica. Disponível em: https://paineira.usp.br/aun/index.php/2018/o9/27/fake-news-e-osimpactos-na-divulgacao-cientifica/ Acesso em: or dez. 2020.

MESQUITA, Ofélia Alencar et al. Fake news: geração, propagação e educação para as redes sociais. Textura, v. 22 n. 52, 2020.

OLIVEIRA, Sara Mendonça Poubel. Disseminação da informação na era das fake news. Múltiplos Olhares em Ciência da Informação, v. I, n. 2, 2018.

ONGARO, Viviane educação em tempo de "fake news": jovens estudantes na era da pós-verdade. Pensacom Brasil, 2019.

PROSCHOLDT Eliane; GIUBERTI Simony. Fake news ameaçam crianças e adolescentes. Disponível em: https://tribunaonline.com.br/fake-news-ameacamcriancas-e-adolescentes Acesso em: or dez. 2020.

SANTOS, Maria Celça Ferreira; MIRANDA, Cícero Anastácio Araújo. Proposta de formação de leitores críticos para o combate às fake news. Revista Eletrônica do GEPPELE. Ano VI, no o8, 2020.

SILVA Tammi Schalm. Fake News: como ensinar os alunos a lidarem com essa realidade? Trabalho de Conclusão de Curso (Especialização em Mídias na Educação). Centro Interdisciplinar de Novas Tecnologias na Educação. Universidade Federal do Rio Grande do Sul, 2018.

TIC Kids Online Brasil: pesquisa sobre o uso da internet por crianças e adolescentes no Brasil 2016. São Paulo: Comitê Gestor da Internet no Brasil, 2017. 